\title{
ENSINO CRÍTICO DE LÍNGUA PORTUGUESA NO IFSP - CAMPUS PRESIDENTE EPITÁCIO
}

\section{CRITICAL TEACHING OF PORTUGUESE LANGUAGE AT IFSP - PRESIDENTE EPITÁCIO CAMPUS}

\author{
Irando Alves Martins Neto *
}

\begin{abstract}
Resumo: Embasado em uma perspectiva crítica de ensino e sociocultural de letramento, este artigo examina o trabalho de um docente de língua portuguesa em duas salas de aula da segunda série do Ensino Médio no Instituto Federal de São Paulo, Câmpus Presidente Epitácio. Objetiva-se discutir de que modo o trabalho do professor dialoga com estudos que compreendam o letramento de um ponto de vista sociocultural e o ensino de língua de uma perspectiva crítica. Para tanto, são apresentadas as propostas do docente, bem como analisadas produções dos educandos. Conclui-se que a prática realizada é coerente com os referenciais teóricos que se defendem neste texto, embora seja possível (e necessário) aperfeiçoá-la, ampliando a relação da escola com outros setores da comunidade que a rodeia, bem como debatendo com o educando o poder da linguagem quanto às lutas de classes, conscientizando-o sobre as injustiças sociais legitimadas por meio da palavra (culta).
\end{abstract}

Palavras-chave: Ensino. Língua Materna. Transformação.

\begin{abstract}
This paper, grounded on theories and studies on literacies and critical education, invites reflection on teaching practices developed in Portuguese lessons delivered to second-year students of High School at Instituto Federal de São Paulo, Presidente Epitácio Campus. The paper aims at comprehending how such teaching practices dialogue with sociocultural studies on literacy and critical pedagogy theory. Thus, the teacher's proposals are presented, and some of the students' tasks are analyzed. The results show that the teacher's practice is consistent with the theoretical framework, although it is possible (and necessary) to improve it, by expanding the relationship between school and other sectors of its community, as well as by raising students' awareness on the power of (standard) language concerning class struggles and social injustices.
\end{abstract}

Keywords: Teaching. Mother Tongue. Transformation.

\section{Introdução}

No processo de planejamento deste texto, veio-me à mente se deveria considerá-lo um relatório de pesquisa ou um relato de experiência em sala de aula. Retomando o trabalho realizado, convenci-me de que se trata mais de uma prática docente do que do desenvolvimento de uma pesquisa científica. Espero que isso, por si só, faça com que o leitor aceite - sem desconfiar da fidedignidade das informações apresentadas - a primeira pessoa ocasionalmente utilizada. Caso tal hibridez textual um relato pessoal em formato de artigo científico - não seja suficiente para aceitá-la, justifico-a pela escolha das teorias que embasam este texto, as quais não somente assumem que a neutralidade é um mito, mas também defendem que o posicionamento ideológico explícito é necessário tanto na pesquisa como na prática docente.

\footnotetext{
* Docente da área de Letras no Instituto Federal de São Paulo, Câmpus Avançado Jundiaí. Doutor em Estudos da Linguagem pela Universidade Estadual de Londrina, mestre em Educação pela Universidade Estadual Paulista e licenciado em Letras (Português/Inglês) pela Faculdade de Presidente Prudente. Email: irando@ifsp.edu.br.
} 
A dúvida acima exposta surgiu por reconhecer na pesquisa-ação uma metodologia que tem como principal característica a transformação social e $\mathrm{o}$ aprimoramento da prática (TRIPP, 2005). Ao elencar cinco tipos de pesquisa-ação, Tripp (2005, p. 458) menciona a modalidade "socialmente crítica", que, nas palavras do autor, "passa a existir quando se acredita que o modo de ver e agir 'dominante' do sistema, dado como certo relativamente a tais coisas, é realmente injusto de várias maneiras e precisa ser mudado". Não se trata, pois, de "fazer melhor o que você já faz, mas como tornar o seu espaço no mundo um lugar melhor em termos de mais justiça social" (TRIPP, 2005, p. 458). A prática aqui relatada aponta, sem dúvidas, o aprimoramento da minha prática docente, resultado de um modo de lecionar por mim antes não contemplado, que busca a conscientização crítica dos educandos a respeito da realidade que os rodeia, bem como possibilidades de transformação de tal realidade por meio da linguagem. A isso, acrescenta-se o fato de que a prática recorreu a teorias "para compreender as situações, planejar melhoras eficazes e explicar resultados", o que, conforme Tripp (2005, p. 450), é importante na pesquisa-ação.

Por que, então, este texto apresenta uma experiência pedagógica, não dados de uma pesquisa científica? Para responder à questão lançada, é preciso saber o que motivou a atividade realizada.

A prática descrita neste artigo é um recorte de uma ação maior, isto é, trago dados de aulas lecionadas apenas em determinado semestre, ainda que eu tenha sido, anteriormente, professor das turmas onde as atividades aconteceram. $\mathrm{O}$ recorte justificase pela mudança em minha atuação docente, ocorrida pelo contato com perspectivas socioculturais de estudos do letramento, como Street (2014) e Kleiman (1995), e com um ponto de vista crítico de ensino de línguas, como Norton (2007) e Shor (2009).

Ao apropriar-me de tais discursos científicos, então, decidi realizar um trabalho que fosse ao encontro de tais bases teórico-filosóficas. Isso significa que, embora tenha havido, a meu ver, aprimoramento da prática e, dentro de alguns limites, transformação da realidade, não houve um objetivo de pesquisa, pois "o processo de mudança [não foi] conduzido por meio da análise de dados" e "o alvo principal da atividade [não foi] a criação de conhecimento teórico ou o aprimoramento da prática" (TRIPP, 2005, p. 452), mas que os educandos compreendessem, com e pela linguagem, sua realidade local, podendo mudá-la.

Se eu considerasse as informações trazidas neste texto como dados de pesquisa científica, cairia no erro de entender todas e quaisquer práticas teoricamente embasadas e que buscam minimizar as injustiças sociais por meio da conscientização crítica como pesquisas científicas, sendo que essa poderia ser a proposta de qualquer disciplina escolar. É por essa razão que julguei necessário, antes de discutir a ação e interpretar seus dados, fazer esse esclarecimento. Por fim, acrescento que não tenho a intenção, com tal esclarecimento, de reduzir o trabalho realizado, já que a prática docente é tão importante quanto a pesquisa. Além disso, a ação desenvolvida e aqui relatada pode servir de um piloto para uma pesquisa-ação que vise à transformação social por meio do ensino de língua materna.

Além disso, ao analisar - com base em teorias - os dados obtidos na prática, eles se tornam objeto de análise científica, ainda que o objetivo inicial não tenha sido esse. É notório salientar que o fato de a prática realizada ter acontecido em contexto espontâneo, desvinculada de objetivos de pesquisa, enriquece a validade dos resultados. Ademais, já havia uma relação entre professor e estudantes, uma vez que, quando 
realizei a prática relatada neste artigo, era professor das turmas há um ano. Desse ponto de vista, ainda que eu tenha planejado e iniciado a prática no papel de professor, avalio, como pesquisador, a minha própria prática em um contexto em que todos os participantes (professor e estudantes) estão inseridos em uma atividade "normal", sem a presença de um estranho - o pesquisador. O observador é, nesse sentido, o próprio observado.

Esclarecido isso, apresento, em seguida, uma breve discussão sobre o ensino de línguas materna com base no conceito de letramento aqui defendido. Posteriormente, exponho o conteúdo trabalhado em sala de aula, analisando cinco atividades produzidas pelos educandos. Finalmente, concluo o artigo (mas não o debate) com algumas considerações finais que retomam a ideia central do texto, refletindo sobre possíveis (e necessárias) alterações na prática docente relatada e sobre a possibilidade (ou não) da realização de trabalho similar em outros contextos de educação básica.

\section{Letramento e ensino crítico de línguas}

O termo "crítica" e suas variáveis têm sido amplamente utilizados no âmbito escolar. Não somente autores da área da Educação - como Libâneo (2012) e Tedesco (2004) -, mas também documentos oficiais nacionais que orientam a prática docente como a Lei de Diretrizes e Bases da Educação Nacional e os Parâmetros Curriculares Nacionais - defendem que um dos papéis da escola é desenvolver o pensamento crítico do educando. No entanto, em geral, pouco se tem discutido acerca de o que é crítica, o que sugere certa cristalização do conceito, que se apresenta de forma ampla e não especificada, significando, talvez, a capacidade do aluno em examinar e julgar determinado conteúdo antes de aceitá-lo como verdadeiro.

No que se refere ao ensino-aprendizagem de línguas, o discurso é o mesmo: julga-se necessário formar estudantes capazes de compreender criticamente o que leem, assim como de produzir textos que os capacitem à inserção social, especialmente no mundo do trabalho. Desse modo, saber ler e escrever, no sentido de codificar e descodificar um código linguístico, torna-se insuficiente. É preciso, então, compreender e produzir textos em diferentes formatos e para diferentes ocasiões sociais, processo chamado de "letramento".

Do ponto de vista sociocultural, letramento é toda e qualquer manifestação da cultura escrita em todo e qualquer tempo e espaço social. Nesse sentido, apesar de haver, em cada língua, um modelo privilegiado de escrita, denominado "padrão", as práticas de letramento são usos sociais da escrita, conforme apontam autores como Street (2014) e Kleiman (1995). Aliás, a própria ideia equivocada, mas normalizada, de que existe um modelo "melhor", "certo" ou "único" de escrita comprova que, não apenas os usos, mas também os significados do letramento, são embebidos de questões sociais, históricas e ideológicas. Discussões sobre a heterogeidade da escrita feitas por autores como Corrêa (2001) defendem a variedade da língua escrita. De maneira similar, trabalhos que debatem a escrita em plataformas digitais (KOMESU \& TENANI, 2009; PAIVA, 2016; BARBOSA \& MARTINS NETO, 2019; MARTINS NETO, 2020) enfatizam o fato de existir variados modelos de escrita em um mesmo contexto social.

Portanto, do ponto de vista sociocultural, o letramento é visto além da habilidade individual e cognitiva de saber ler e escrever. No entanto, como pontua Soares (2011), 
em sua dimensão social, há duas tendências de letramento: uma progressista (fraca) e outra revolucionária (forte).

De acordo com a autora acima citada, a tendência fraca leva em conta as habilidades e conhecimentos considerados necessários para que o indivíduo funcione adequadamente na sociedade, isto é, para se "encaixar" no mundo tal como ele é, aceitando-o. Norton (2007) explica que esse conceito de letramento é um modelo dominante, adotado por governos, elaboradores de políticas públicas e pela população em geral.

Radical e revolucionária, a tendência forte, por sua vez, compreende que "a leitura e a escrita são ferramentas para transformar relações e práticas sociais consideradas indesejáveis ou injustas" (SOARES, 2011, p. 37). Para Norton (2007), no âmbito escolar, essa concepção é adotada somente por alguns educadores.

Entende-se que o que Soares (2011) chama de "tendência forte" é tratado, por muitos autores, como "letramento crítico" - Norton (2007); Gregory e Cahill (2009); e Shor (2009), por exemplo. Mas o que é ser crítico?

Gregory e Cahill (2009) argumentam que o ensino da fala, leitura e escrita deve estar associado a uma forma de questionar, discutir, debater o mundo onde se vive. De modo similar, Shor (2009), citando trabalho de Anderson e Irvine de 1993, defende que o letramento crítico é entendido como a prática de leitura e de escrita sendo parte de um processo de conscientização em que o sujeito se vê historicamente construído dentro de relações de poder específicas. Shor (2009, p. 282, tradução livre) acrescenta que o letramento crítico é o uso da língua que questiona a construção social de si próprio: "quando somos criticamente letrados, examinamos o avanço de nosso desenvolvimento a fim de desvelar os posicionamentos subjetivos que nos fazem compreender e agir no mundo".

Em suma, os autores anteriormente citados defendem que o letramento crítico tem estreita relação com conscientização crítica, isto é, com a compreensão apurada da realidade, levando em conta as relações de poder que estruturam toda e qualquer prática social. Crítica, então, é questionamento, problematização e conscientização do mundo, que é socialmente injusto. Seria "apenas" isso?

Shor (2009) argumenta que o letramento crítico desafia o status quo, na tentativa de descobrir caminhos alternativos para o desenvolvimento social e pessoal, ao passo que Norton (2007) afirma que os educadores interessados no letramento crítico pensam o texto escrito - e qualquer forma de representação de sentidos - como um espaço de lutas, negociações e mudanças. Seguindo a mesma linha de raciocínio, Gregory e Cahill (2007) destacam que o letramento crítico é uma forma de ler e escrever história, no sentido de transformar o mundo em um lugar com menos desigualdade social.

Em resumo, Shor (2009), Norton (2007) e Gregory e Cahill (2007) concordam que ser criticamente letrado é ter consciência da realidade - que é injusta - e criar meios - mediante práticas discursivas - para transformá-la em um espaço mais justo. Crítica é, nessa perspectiva, conscientização mais ação transformadora.

Analisar discursos de maneira crítica é uma forma eficaz de promover a conscientização acerca da realidade. Ramalho (2012), por exemplo, apresenta resultados de uma experiência a partir de um trabalho com leitura, com o objetivo de debater com alunos de estágio em curso de licenciatura a importância de se promover a conscientização crítica da linguagem desde o ensino básico. 
Sem julgar o trabalho de Ramalho (2012) - já que se trata de uma experiência particular com atividades de leitura, muito necessárias para promover o pensamento crítico -, é preciso entender que a promoção de consciência crítica não basta quando a proposta educacional é o desenvolvimento de ações transformadoras. Uma vez consciente da realidade injusta, é importante criar meios de mudá-la. No ensino de línguas, o processo de transformação da realidade é possível principalmente por meio de produção de textos que denunciem o mundo tal como ele é (está), numa tentativa de convencer o "outro", de desconstruir conceitos e dogmas, de dar voz ativa àqueles que são historicamente silenciados. Em outras palavras, é possível, por meio do ensino de línguas, não apenas conscientizar os educandos acerca de como a linguagem é utilizada para marginalizar certos grupos, mas também apontá-la como instrumento de libertação, de esperança de um mundo melhor. Com isso, os educandos podem perceber a linguagem como instrumento de luta.

Fairclough (1989) sugere uma proposta com leitura e escrita, mostrando-nos um trabalho possível de conscientização da linguagem, ao tratar o educando como protagonista que escreve sua própria história, refletindo sobre suas experiências. Similarmente, Clark, Fairclough, Ivanic e Jones (1996, p. 52) propõem um trabalho que inclui, além de conscientização social do discurso e conscientização crítica da diversidade, a "consciência de, e prática para a, mudança".

Para Clark, Fairclough, Ivanic e Jones (1996), a conscientização é uma etapa para a transformação. No caso do ensino de língua (materna), a leitura crítica de textos mostra-se como importante instrumento de conscientização crítica, ao passo que a produção de textos (oral ou escrita), quando retrata e denuncia a realidade da comunidade dos alunos e/ou reivindica melhores condições de vida, é ferramenta essencial de transformação social.

É importante pontuar que a consciência crítica, por meio da leitura, também propicia transformação, pois o sujeito leitor, que agora vê a realidade de outro ponto de vista, é transformado. Do mesmo modo, a produção de texto, uma recriação da realidade, pode ser modo de conscientização de si mesmo (em um processo de autorreflexão) e do "outro", que lerá tal produção. Não se trata, pois, de um processo linear e fragmentado (primeiro a leitura, conscientização, depois a escrita, transformação), mas dialógico e dialético.

Observa-se, com isso, que a abordagem crítica de ensino de leitura e escrita tem estreita relação com os pressupostos de Freire (2011; 2015). De acordo com o educador, a leitura da palavra implica sempre a percepção crítica, uma espécie de interpretação e "re-escrita" do lido, pois, "do ponto de vista crítico e democrático (...), o alfabetizando, e não o analfabeto, se insere num processo criador, de que ele também é sujeito" (FREIRE, 2011, p. 41). Em outro trabalho, Freire (2015) acrescenta que a criação interpretativa do mundo por meio da palavra é uma luta constante em que a classe dominante, ao estabelecer os sentidos da realidade a seu favor, oprime a classe marginalizada. E essa classe marginalizada é, em geral, pobre, negra, mulher e homossexual.

É por essa razão que uma das possibilidades da escola, por meio de ensino crítico, é humanizar os educandos, na tentativa de conscientizá-los acerca de outros sentidos do mundo para que possam transformá-lo, rompendo com a posição de oprimido, sem se tornarem, todavia, opressores. 


\section{Relato de uma experiência que deu certo (e pode ser aperfeiçoada)}

A prática relatada aconteceu no Instituto Federal de Educação, Ciência e Tecnologia de São Paulo (IFSP), Câmpus Presidente Epitácio, para duas turmas da segunda série do Ensino Médio, sendo elas integradas ao ensino técnico: uma de Informática (30 alunos) e uma de Mecatrônica (32 alunos). São destinadas quatro aulas de Língua Portuguesa a cada sala. A experiência aqui relatada ocorreu no segundo semestre de 2016.

O conteúdo programático da disciplina para o segundo semestre da segunda série do Ensino Médio, de acordo com o Projeto Pedagógico do Curso, é: Realismo, Naturalismo, Parnasianismo, Simbolismo, frase, oração, período, termos essenciais da frase (sujeito e predicado), termos ligados ao verbo (objeto direto, objeto indireto, objeto direto preposicionado, objeto direto e objeto indireto pleonásticos, pronomes oblíquos como objeto, adjunto adverbial), termos ligados ao nome (adjunto adnominal, complemento nominal, aposto e vocativo), crítica, editorial, entrevista e mesa-redonda.

Com base nesses itens, elaborei um cronograma para 80 aulas semestrais, incluindo, ainda, outras produções de texto: uma reportagem (que estava prevista para o primeiro semestre, mas não foi realizada por falta de tempo) e duas redações nos moldes propostos pelo ENEM (a pedido dos alunos no início do ano). Além disso, o editorial foi substituído por um artigo de opinião.

Sem prova escrita, os estudantes foram avaliados, durante o semestre, por meio dos seguintes instrumentos: seminário, debate de livro literário, exposição de fotos, entrevista, crítica, reportagem, artigo de opinião, redações (formato exigido pelo ENEM), mesa-redonda e participação em grupo.

A proposta era que, a partir do estudo de textos do Realismo e Naturalismo, os estudantes pudessem compreender elementos de crítica social das obras desse período, refletindo, assim, sobre os problemas sociais presentes em sua comunidade e pensando em possibilidades de mudança. Para tanto, foram intercalados contos de Machado de Assis e o romance $O$ cortiço, de Azevedo, com abordagem de aspectos gramaticais e gêneros previstos no conteúdo programático. Cabe esclarecer que o objetivo não era transformar o texto literário em pretexto para ensinar gramática, mas, mediante análise de aspectos linguísticos (por se tratar de uma aula de língua), partir para a interpretação do texto literário e da crítica social.

Antes de apresentar as atividades de letramento que visaram à promoção de conscientização crítica e à transformação social, descrevo brevemente, no item posterior, como as aulas foram lecionadas metodologicamente.

\subsection{Organização do trabalho (colaborativo)}

No primeiro dia de aula, além da reelaboração do cronograma, foram formados os grupos de trabalho (GT). Isso porque uma das propostas era que a maioria dos trabalhos fosse realizada de maneira colaborativa. Todos os grupos, no início das aulas, se juntavam para realização das tarefas. Foi interessante notar que a turma de Mecatrônica, durante todo o semestre, já se reunia antes da chegada do professor à sala. Além disso, cinco dos seis GT nomearam-se Gossipy Girls, Os Herói, Hippie Catuaba Selvagem, As meninas, Goiaba. Esses fatos mostram o engajamento dos estudantes nas 
aulas propostas. Já com a turma de Informática, era preciso, quase sempre, relembrá-los e, em alguns casos, insistir para que se reunissem. Isso mostra um movimento de resistência às atividades propostas.

Esse trabalho em grupo era parte da atividade avaliativa e, por isso, em todo encontro, cada aluno era avaliado levando-se em consideração três critérios, conforme a ficha abaixo:

Quadro 1 - Ficha de avaliação de trabalho em sala de aula.

\begin{tabular}{|l|l|l|l|}
\hline Nome do aluno: & SIM & NÃO & Parcialmente \\
\hline $\begin{array}{l}\text { Trabalhou de forma colaborativa, respeitando o outro? } \\
\text { (peso 1) }\end{array}$ & & & \\
\hline Realizou as atividades propostas pelo professor? (peso 2) & & & \\
\hline $\begin{array}{l}\text { Contribuiu para o resultado final do GT ou apenas } \\
\text { aceitou as opiniões dos demais colegas? (peso 1) }\end{array}$ & & & \\
\hline
\end{tabular}

Fonte: atividade elaborada pelo professor (2016).

Um exemplo desse trabalho em grupo pode ser ilustrado com as leituras dos contos de Machado de Assis. Por exemplo: com o último parágrafo de "A cartomante" ocultado, os alunos leram, individual e silenciosamente, o conto. Ao finalizar, cada GT criou um fim para o texto, compartilhando-o com toda a sala. Em geral, todos os integrantes do grupo envolveram-se com a produção e quase todos os doze grupos das salas optaram por um fim inesperado e bastante diferente do original, como se observa na produção de Hippie Catuaba Selvagem:

Quadro 2 - Fim de "A cartomante".

Sem responder Camilo, Vilela o conduz pela casa até um quarto escuro pequeno, onde a pouca luz os capacitava de ver apenas os olhos brilhantes de Rita, brilhantes e vermelhos como os rubis que enfeitavam a roupa da velha cartomante.

O marido traído acende a luz amarelada do quarto, e Camilo, sem acreditar no que estava acontecendo, se depara com Rita presa na cama, com seu corpo nú e cabelos luxuosamente bagunçados.

Enquanto Vilela despia-se e dominava seu antigo amigo, Rita, com sua voz macia e sensual, diz: "assim como há mais cousas no céu e na terra do que sonha a filosofia, há mais prazeres no corpo de uma mulher do que dois homens podem imaginar".

Fonte: Grupo Hippie Catuaba Selvagem (2016).

Constata-se que o texto elaborado pelos estudantes leva em conta não apenas o enredo do conto, mas também se preocupa com a descrição do ambiente ("quatro escuro pequeno"; "luz amarelada do quarto") e dos personagens ("olhos brilhantes"; "marido traído", "cabelos luxuosamente bagunçados"; "voz macia e sensual"). Além disso, os alunos recuperam a personagem cartomante, estabelecendo uma relação, por meio de 
comparação, entre ela e Rita, o que intensifica o caráter sobrenatural da história e do que está por vir (a proposta de um triângulo amoroso). Por fim, os estudantes recuperam também a fala de Hamlet apresentada no início do conto e repetida quando Camilo decide visitar a cartomante.

Compartilhado o texto original, discutimos e desvelamos as dicas que o narrador dá para levar o leitor a pensar em um desfecho diferente do proposto pelo autor. Feito isso, nas aulas seguintes, cada grupo ficou responsável por analisar um aspecto do conto: 1) tempo; 2) espaço; 3) foco narrativo; 4) personagens; 5) enredo; e 6) ironia.

Para análise dos elementos da narrativa, os estudantes receberam trechos do texto de Franco Junior (2003). Quanto à ironia, o grupo responsável pesquisou a definição no livro didático ou no celular, uma vez que a figura de linguagem havia sido revisada no primeiro semestre.

Embora feitas em grupos, foi pedido que todos registrassem as "respostas" para utilizá-las na tarefa posterior. Depois disso, cada aluno de cada GT deveria trocar de grupo, de modo que, em todo grupo novo formado, houvesse um elemento analisado diferente. Assim, cada grupo teria alguém compartilhando um aspecto analítico do texto.

De modo geral, o trabalho em equipe foi enriquecedor e os alunos se envolveram nas atividades de leitura e produção textual, como pode ser visto nas análises apresentadas posteriormente.

\subsection{Leitura e conscientização da realidade}

Além dos contos de Machado de Assis, os alunos leram, no terceiro bimestre, o romance $O$ cortiço, de Azevedo. A ideia era que, a partir de tais textos, principalmente do romance, eles compreendessem diversas críticas sociais presentes na narrativa e se despertassem para os problemas sociais que os rodeiam.

Para o debate do livro, dividimos a obra em seis partes, cada qual para um grupo. A tarefa consistiu em: 1) uma breve síntese oral dos capítulos que compuseram a parte, relacionando-a com as características do movimento ao qual o texto pertence; 2) apresentação de um intertexto (literário ou não); e 3) comentários dos demais grupos a respeito da parte debatida. Surgiram temáticas como fofoca, sexo e gênero, mas a ênfase foi na relação de poder entre habitantes de um mesmo espaço, como em condomínios fechados, favelas, desapropriação e relação entre síndicos e condôminos. O bimestre finalizou com o debate da última parte do livro.

Em resumo, os estudantes foram relacionando, aos poucos, as temáticas dos textos literários estudados em sala com a realidade deles. Com a leitura dos contos, essas associações aconteceram de maneira mais ampla, pensando a realidade brasileira como um todo ou o ser humano em geral, ao desvelar temas como traição, maldade, ceticismo, inveja, pessimismo, morte, oportunismo, egoísmo, relações de poder entre discursos científico (médico) e popular. Com a leitura do romance, essas relações foram se estreitando, de modo que as temáticas da obra se aproximaram mais de seus cotidianos.

$\mathrm{Na}$ primeira aula do quarto bimestre, os alunos fizeram uma apresentação expondo fotos que revelavam problemas de sua cidade. Cada grupo escolheu um problema, sendo que a destinação imprópria de resíduos sólidos foi o mais votado. Os outros temas foram: mobilidade urbana, acessibilidade, iluminação pública, desemprego, inundação e queimada. 
A aula seguinte foi disponibilizada para elaboração do roteiro de uma entrevista, também sobre problemas de Presidente Epitácio, cujos dados serviriam para as seguintes produções de texto: reportagem, artigo de opinião e mesa-redonda.

O trabalho com as produções acima citadas foi intercalado com aulas expositivas de análise sintática, visto que os educandos precisaram de tempo para agendar as entrevistas e transcrevê-las. Ademais, com a chegada do ENEM, foram disponibilizadas aulas para escrita e reescrita das redações.

As entrevistas foram transcritas e entregues impressas na mesma aula em que os estudantes apresentaram uma ideia geral dos dados coletados. Os alunos entrevistaram autoridades (vereadores, secretários e diretores), comerciantes e membros da comunidade. Em geral, os grupos concluíram que a maior parte dos problemas da cidade é de responsabilidade da prefeitura, que não fiscaliza ou não elabora ações em relação à destinação indevida do lixo, péssima iluminação pública, falta de escoamento de água pluvial, necessidade de construção de ciclovias, falta de rampas na entrada de lojas ou em calçadas de bairros afastados etc. Reconheceram também que, principalmente no que tange ao lixo, há grande falta de conscientização da população, uma vez que a prefeitura tem feito algumas ações a esse respeito.

$\mathrm{Na}$ transcrição abaixo, trecho da entrevista apresentada pelo grupo Os Herói, nota-se tom de crítica e indignação por parte do aluno-entrevistador, que questiona a forma de protesto do entrevistado:

Quadro 3 - Entrevista sobre problemas da cidade.

Aluno-entrevistador: O que o senhor acha sobre os problemas da cidade?

Cidadão: Grave. Falta de boa vontade, de força política.

Aluno-entrevistador: [...] candidato que o senhor votou para vereador... o senhor votou nele [...] por alguma proposta em relação a esses problemas da cidade?

Cidadão: Não, não votei; não voto mais em ninguém. Voto em branco [...]. É um protesto.

Aluno-entrevistador: É um jeito muito interessante de protestar, né? Não votar...

Fonte: Grupo Os Herói (2016).

A pergunta inicial elaborada pelo grupo ("o que o senhor acha sobre os problemas da cidade?") é tendenciosa, pois nega a possibilidade de Presidente Epitácio não apresentar problemas. Assim, o entrevistado é levado a concordar com o entrevistador, cabendo ao cidadão tão somente dar a sua opinião a respeito dos problemas que existem, sim, no município. Apesar de o entrevistado seguir a lógica da pergunta, afirmando que os problemas são "graves", ele vai além da resposta provavelmente esperada pelos elaboradores da pergunta e responsabiliza o poder público por tais problemas ("falta de [...] força política"). Nesse contexto, é interessante notar o movimento do aluno-entrevistador que, apesar de concordar com o tom do entrevistado (sugerindo que cabe ao poder legislativo criar propostas de melhoria), cobra do cidadão um voto consciente. Ao saber que o entrevistado votou em branco, o aluno mostra-se crítico e indignado, afirmando, em tom talvez irônico, que "não votar" é um jeito muito interessante de "protestar". Desse modo, a ideia implícita defendida pelo aluno, de que pelo voto é possível provocar melhorias, gera um efeito de sentido de que o entrevistado 
não exerce o seu papel de cidadão de maneira consciente e, portanto, não tem o direito de reclamar dos problemas da cidade.

Como dito, as informações das entrevistas serviriam de dados para as demais produções de texto: reportagem, artigo de opinião e mesa-redonda. Nesse sentido, o trabalho feito até então teve como intuito despertar a consciência crítica da realidade nos educandos, o que foi feito por meio de grupos de trabalho. O próximo passo seria, então, transformar essa realidade por meio de textos (orais e escritos).

\subsection{Produção de texto de transformação social}

Inicialmente, as demais produções escritas seriam expostas no mesmo dia da mesa-redonda. A ideia era promover um evento aberto à comunidade para divulgação de todo o trabalho (fotos, entrevistas, reportagens e artigos de opinião), tendo como encerramento a mesa-redonda.

A partir dos dados da entrevista, então, os GT produziram uma reportagem sobre o problema identificado no início do bimestre. Em geral, os grupos conseguiram produzir textos coerentes, com ênfase no problema levantado e na cidade de Presidente Epitácio. Alguns grupos, no entanto, expuseram o tema de modo geral, direcionando muito pouco para o município. Além disso, muitos grupos tiveram dificuldades em citar falas das entrevistas no corpo da reportagem, de modo que a estrutura composicional do gênero se comprometeu. Sendo assim, alguns GT tiveram que reescrever o texto mais de uma vez. Lê-se, abaixo, trecho da primeira versão de uma reportagem de um GT de Informática que ilustra esse desvio:

Quadro 4 - Trecho da primeira versão de uma reportagem de um GT.

\section{Inundações: um problema silencioso}

A falta de planejamento Urbano é um problema que assola boa parte das cidades do Brasil. São Paulo é um exemplo desse caos: poluição, engarrafamento e construções em áreas irregulares são pontos que chamam a atenção. Embora não seja o centro de holofotes, há um outro problema consideravelmente silencioso, mas que quando associado a grandes precipitações, causa enormes estragos: as inundações, que são resultados da ausência ou da escassez de sistemas de escoamento aquático.

As inundações afetam também cidades pequenas, como é o caso de Presidente Epitácio, situada no interior do Estado de São Paulo na fronteira com Mato Grosso do Sul. Na cidade, o bairro mais afetado com as mesmas é o Renascer, que foi fundado recentemente. Lá, o problema também tem a mesma causa: sistemas de escoamento aquático não- suficientes. Insuficiência é essa que é responsável por inúmeros transtornos aos moradores como o seu José que vive no local a cerca de 3 anos.

José: "Aqui não tem rede de água fluvial, então, quando chove não tem onde a água desaguar. Aí, fica bastante água, vem até aqui na porta do comércio".

Entrevistadora: A prefeitura já foi informada sobre isso?

José: "Sim, já foi. Diz que vão tomar as providências, mas até então estamos aguardando". 
Sem melhora na situação, os moradores, como medida emergencial, improvisaram uma valeta em uma propriedade privada (...).

Fonte: alunos da turma de Informática (2016).

Observa-se que, embora a estrutura do gênero reportagem esteja inadequada, a linha argumentativa é bem elaborada, aspecto corrente na maioria das reportagens. É importante mencionar que os alunos leram uma notícia e uma reportagem que tratavam de um mesmo tema, como forma de ampliar o repertório sobre o assunto, bem como de reconhecer a estrutura do gênero. Ademais, os alunos foram ensinados a usar as falas das entrevistas no corpo do texto, além de citar o sobrenome ou nome completo do entrevistado. Desse modo, é possível observar que os estudantes estavam muito mais preocupados com o conteúdo do que com a forma, o que é extremamente positivo em um trabalho como o proposto, que visa à promoção de conscientização crítica e à transformação social.

O texto anteriormente apresentado parte de uma ideia praticamente inquestionável (muitas metrópoles brasileiras enfrentam problemas de planejamento urbano) para defender que tais problemas não estão presentes apenas em grandes cidades. Isso é enfatizado por meio da utilização do termo "também", em "as inundações afetam também cidades pequenas", construindo um efeito de sentido que permite o leitor inferir que a inundação em pequenas cidades é um problema silenciado, mas que deveria ser mais evidenciado.

A pergunta feita pela aluna-entrevistadora ao senhor José (“a prefeitura já foi informada sobre isso?") é um tanto quanto tendenciosa. Além de sugerir ao entrevistado que a prefeitura deve ser avisada sobre os problemas de inundações, a aluna sugere que cabe à administração pública da cidade resolver esse problema. Ademais, o uso do termo "já" contribui para a geração de um efeito de sentido que responsabiliza sobretudo o poder público. O cidadão "já" fez a sua parte em denunciar o problema; agora cabe à prefeitura fazer a sua. Uma pergunta como "a prefeitura foi avisada sobre isso?", sem a utilização de "já", amenizaria a crítica à administração pública da cidade.

Em relação ao artigo de opinião produzido pelos estudantes, destaco o texto abaixo:

Quadro 5 - produção de artigo de opinião sobre acessibilidade.

\section{A gramática da (in)acessibilidade: um substantivo abstrato para sujeitos inexistentes}

Em 1948, quando a Organização das Nações Unidas (ONU) promulgou a Declaração Universal dos Direito Humanos, o documento garantia no primeiro artigo que todos os seres humanos nascem livres e iguais em dignidade e em direitos. E devem agir uns para com os outros em espírito de fraternidade.

Fraternidade está diretamente relacionada ao afeto, ao cuidado e à empatia, sentimentos não incentivados em um meio onde o individualismo e o egocentrismo estão sempre em primeiro plano e a pluralidade é restrita, recorrentemente, à gramática. 
O planeta Terra tem hoje cerca de 7,5 bilhões de pessoas que, devido às características genéticas e à influência que sofrem do meio onde habitam, são completamente singulares, mas que, quando unidas, formam uma rede de relacionamentos capaz de dar sentido à vida de cada um. As diferenças nos unem!

Embora romântica na teoria, a realidade é, muitas vezes, antagônica. Para garantir a igualdade $\mathrm{e} o$ respeito às diferenças e às necessidades de cada ser, é que existem os direitos.

A Constituição Federal Brasileira de 1988 estabelece no Art. $5^{\circ}$ a igualdade entre todos os cidadãos perante a lei, sem distinção de qualquer natureza, garantindo-lhes a inviolabilidade do direito à vida, à liberdade, à igualdade, à segurança e à propriedade, acrescentando no parágrafo 15 o direito à livre locomoção no território nacional em tempo de paz, podendo qualquer pessoa nele entrar, permanecer ou sair com seus bens.

Será?

O CENSO realizado pelo IBGE em 2000 apontou que cerca de $14.5 \%$ da população brasileira da época, em torno de 170 milhões, era deficiente, o que correspondia a 25 milhões de pessoas. As discussões dessas informações levam-nos ao seguinte questionamento: o que é acessibilidade?

Gonzales e Matos afirmam que "acessibilidade são as condições e possibilidades de alcance para utilização, com segurança e autonomia, de edificações públicas, privadas e particulares, seus espaços, mobiliários e equipamentos urbanos, propiciando a maior independência possível e dando ao cidadão deficiente ou àqueles com dificuldade de locomoção o direito de ir e vir a todos os lugares que necessitar, seja no trabalho, estudo ou lazer, o que ajudará e levará à reinserção na sociedade".

Iniciativas públicas e privadas trabalham em políticas inclusivas que, embora pareçam ter vindo de almas iluminadas, são somente tentativas, ainda em construção, de atender às próprias leis estabelecidas na Carta Magna, como os artigos 227 e 244 que estabelecem a construção e adaptação de logradouros públicos ou privados a fim de garantir acesso adequado às pessoas com deficiência, respectivamente.

Problemas relacionados à falta de acessibilidade atingem todo o Brasil, desde grandes centros urbanos até municípios pequenos, situados no interior, como é o caso de Presidente Epitácio, nossa Joia Ribeirinha!

A ausência de rampas, de modo geral, é um dos principais pontos. Seja nos quarteirões, seja no comércio, as rampas não são de fácil acesso e são escassas, sendo que, quando existem, estão completamente carentes de reparos ou até mesmo são muito íngremes. Além disso, as rampas estão concentradas na área central da cidade e a mesma não é formada somente por seu centro.

As ruas de paralelepípedos, também sem reparos, são causadoras de fortes trepidações $\mathrm{e}$, consequentemente, de diversos danos materiais, como acontece com as cadeiras de rodas, que têm o tempo de vida útil reduzido.

Dentre outros problemas, é possível identificar a falta de vagas para deficientes e de fiscalização das mesmas e das rampas ou passarelas.

Definitivamente, a amada e idolatrada pátria não estava e não está, visto que o atual 
cenário brasileiro não apresentou mudanças significativas, adaptada às necessidades de seus filhos, conclusão clara ao observarmos que "acessibilidade" é um substantivo abstrato no cotidiano de cidadãos considerados sujeitos inexistentes.

Fonte: aluna do curso de Informática (2016).

O texto utiliza dados de fontes reconhecidas, como a Declaração Universal dos Direitos Humanas e a Constituição Federal Brasileira, para argumentar que todos os seres humanos, deficientes ou não, têm os mesmos direitos. Esses dados corroboram a tese de que Presidente Epitácio não está adequadamente estruturada para propiciar o acesso a deficientes físicos.

Em um jogo de palavras, o título apresenta a "acessibilidade" como substantivo abstrato, utilizado no texto não para classificar mofologicamente o termo, mas para caracterizá-lo como de existência dependente, ou seja, nesse caso, a acessibilidade depende, para existir, de medidas concretas tomadas pela administração pública. Nesse caso, trata-se da administração pública da cidade de Presidente Epitácio. Apresenta, também, a expressão "sujeitos inexistentes" como crítica à forma como os deficientes físicos são geralmente tratados. Esse jogo de palavras apresentado no título é confirmado pelo leitor nas últimas linhas do texto: “acessibilidade' é um substantivo abstrato no cotidiano de cidadãos considerados sujeitos inexistentes". Trata-se, portanto, de texto que descreve o problema da acessibilidade em Presidente Epitácio de maneira crítica.

Em relação à mesa-redonda, a turma de Informática escolheu o tema "acessibilidade", e a de Mecatrônica, "mobilidade urbana" e "destinação de resíduos sólidos". Assim, organizamos a mesa-redonda "Problemas urbanos de Presidente Epitácio: acessibilidade, mobilidade urbana e destinação de resíduos sólidos" em parceira com a professora de Geografia do Câmpus. Essa parceria ocorreu porque, durante a elaboração dos trabalhos escritos, os educandos relataram que a professora de Geografia havia solicitado atividade similar, mais especificamente sobre problemas urbanos em Presidente Epitácio. Os alunos pediram para apresentar os mesmos trabalhos às duas disciplinas, em razão da grande quantidade de atividades extraclasses solicitadas pelos professores. Além de concordar com a solicitação dos alunos, a docente de Geografia contribuiu ativamente na organização da mesa-redonda.

Os membros da mesa foram escolhidos pelos próprios alunos: um membro da comunidade (uma cadeirante), um vereador (pai de uma aluna) e o presidente da Associação Comercial e Industrial de Presidente Epitácio (ACIPE) foram as pessoas escolhidas pela turma de Informática. A prefeita eleita para o exercício 2017-2020, o diretor do meio-ambiente e outro vereador foram os escolhidos pela turma de Mecatrônica. Ao questionar o fato de não convidar o então atual prefeito, os estudantes disseram que ele não apareceria, pois "sempre que é chamado pelo jornal não vai nem manda representante". Cabe dizer que os dois vereadores escolhidos foram reeleitos para 2017-2020. A prefeita eleita, convidada, também não compareceu.

Depois disso, os educandos elaborariam os convites e entregariam aos convidados. No entanto, ao conversarmos com a gerente educacional sobre um espaço para realização da mesa-redonda e equipamentos necessários, ela solicitou que os convites fossem feitos em forma de ofício e assinados pelo diretor do Câmpus.

Foi publicado, ainda, um convite à comunidade no site do Câmpus. Todavia, não consideramos que a camada da comunidade que mais sofre com os problemas a serem debatidos não costuma acessar a página. Portanto, avaliamos que deveríamos ter 
efetivado outras formas de divulgação, como afixação de cartazes em escolas públicas e distribuição de panfletos nos bairros.

Em sete de dezembro, então, foi realizada a mesa-redonda. Dois motivos, no entanto, impossibilitaram a exposição dos trabalhos escritos dos alunos: 1) os artigos de opinião ainda não haviam sido corrigidos e alguns GT ainda não haviam entregado a segunda versão da reportagem; e 2) haveria pouco tempo para debate após as falas dos membros da mesa. Sendo assim, decidimos que a melhor opção seria tentar publicar tais trabalhos em jornais locais. No fim de dezembro de 2016, o jornal Debate Notícias concordou em publicar, depois de corrigido, o primeiro artigo de opinião anteriormente analisado ("A gramática da (in)acessibilidade: um substantivo abstrato para sujeitos inexistenttes") assim que possível, mas não respondeu aos e-mails posteriores.

Antes de a mesa iniciar-se, a gerente educacional abriu o evento, explicando aos presentes que se tratava de um trabalho desenvolvido pelos alunos da segunda série. Em seguida, apresentei algumas fotos que ilustravam os problemas identificados pelos estudantes. Depois, uma aluna do curso de Informática abriu a mesa, apresentando os membros e convidando-os à composição da mesa-redonda.

Com duração de 02:08:51, o evento contou com a presença de 60 alunos, 05 professores, 02 técnicos administrativos e 01 membro da comunidade. Dos 60 alunos, 58 eram da segunda série, sendo que faltaram 04 estudantes da Informática e nenhum da Mecatrônica. O único membro da comunidade era mãe de uma aluna do curso de Informática.

A aluna que fez o papel de moderadora voluntariou-se para tanto quando eu perguntei, abertamente, quem poderia fazê-lo. Não se trata de aluna que se destaca em notas escolares, mas é estudante querida pelo grupo (chamada de mãe pelos alunos da Informática) e que esteve à frente de outros eventos, como a organização da formatura. Trata-se, então, de aluna desinibida.

Ao fim da fala de cada membro da mesa, a discente agradecia pelas contribuições e, depois que todos falaram, a aluna ressaltou, antes de abrir para o debate, pontos importantes mencionados na mesa:

Quadro 6 - Mediação em mesa-redonda.

Eu gostaria de ressaltar um pouco a questão que foi bastante comentada aqui, mas que cabe a nós, como cidadãos, a desconstrução dessa cultura de descarte de lixos em locais indevidos. E não só a essa cultura do descarte, mas também o respeito com as pessoas que precisam... os deficientes, em todas as áreas da deficiência... E também outra coisa que a Dona $R$. comentou é que a acessibilidade aqui em Epitácio, o maior foco dela está na avenida, seja em rampa de acesso quanto em sinalização; e isso não é bom, porque as pessoas nem sempre moram na avenida, como ela comentou. Agora eu gostaria de abrir para as pessoas que gostariam de falar alguma coisa...

Fonte: aluna do curso de Informática (2016).

Apesar das modalizações linguísticas, o comentário da mediadora apresenta duas críticas. Uma delas se refere ao descarte de resíduos sólidos. No trecho "eu gostaria de ressaltar um pouco a questão que foi bastante ressaltada aqui, mas que cabe a nós, como 
cidadãos...", observa-se a opinião da aluna em relação à "cultura do descarte". A partir da conjunção adversativa "mas", a estudante parece estabelecer uma distância entre o que foi debatido na mesa, por "especialistas", e o que acontece na prática cotidiana. Tal conjunção contribui para o efeito de sentido de que cabe a cada pessoa fazer a sua parte, ou seja, a aluna deixa claro que o tratamento correto ao lixo é também responsabilidade da população. A segunda crítica se refere à falta de acessibilidade em Presidente Epitácio. Neste caso, nota-se que a estudante deixa transparecer a sua opinião de que esse problema é de responsabilidade da administração pública (citando áreas da cidade), mas não menciona isso explicitamente, preservando sua face diante dos vereadores que compõem a mesa. Além disso, a mediadora relativiza o problema da falta de acessibilidade, optando pelo sintagma "e isso não é bom" em vez de "e isso é ruim", por exemplo.

Ao abrir para participação do público, já era quase horário de encerrar a mesa. Sendo assim, apenas cinco pessoas conseguiram fazer perguntas: dois alunos (ambos de Informática), duas professoras e um membro da comunidade (mãe de uma aluna). Destaco a fala do membro da comunidade, que questiona a falta de acessibilidade a deficientes físicos:

Quadro 7 - Participação do público na mesa-redonda.

Bom dia. Meu nome é Re. e eu sou professora da rede municipal há 27 anos e há quatro anos, praticamente, eu trabalho só com crianças especiais da minha escola e de algumas outras escolas. Então, eu vou direcionar minha palavra ao A. [vereador, um dos participantes que compuseram a mesa], porque você foi eleito vice-prefeito, né? Então, como você, digamos que... é meu patrão, vamos dizer assim, e eu trabalho na rede municipal. Então, eu gostaria que você tivesse uma preocupação. E gostaria de levantar vocês também alunos, porque... teve o B. [outro membro da mesa], ele disse que vocês alunos são o futuro. E eu acho que vocês não são o futuro; vocês são o presente, porque quando a $R$. [membro da mesa - cadeirante] precisa se mobilizar, ela precisa se mobilizar agora, ela não precisa se mobilizar amanhã (...). Eu acho que a gente precisa se mobilizar é agora. Eu tive um aluno, R., que ele era cadeirante. E nós fizemos um pedido de rampa para minha escola para que ele pudesse ir para o parque muito mais fácil (...). Esse moleque saiu da minha escola já fazem... três anos. Ele ficou na minha escola três anos e a rampa [risos] ainda não está pronta, certo? Então esse negócio que é para o futuro, é para amanhã, isso é utopia, porque o negócio a gente está vivendo é hoje (...). Ele precisa para hoje, porque é o que ele está vivendo. A realidade dele é hoje. E quando a N. [filha de Re., aluna do curso de Informática] falou para mim que essa mesa levantaria isso, eu me ofereci. Eu disse: eu posso ir? Porque essa é a minha briga constante na minha escola (...). Que nem você [apontando para R.] disse que o prefeito precisava ler a constituição. Ele não precisa ler só a constituição, ele precisa se conscientizar, porque de lei... está cheio de lei (...), que não está vigorando, que só fica no papel. As pessoas precisam de conscientização. As pessoas (...) precisam de atitude. E é isso que eu estou pedindo para vocês: atitude (...). Não estou aqui acusando, não estou apontando ninguém (...). Digamos que é a hora talvez que eu tenha para me manifestar diante de duas autoridades de nosso município. Você está como vereador há tantos anos no nosso município, e essa lei há tantos anos já existe. Então, eu acho que como vereador, precisa, sim, ler um pouquinho mais, buscar, querer fazer mais 
pelas pessoas que necessitam um pouquinho mais de atenção (...).

Fonte: participante (2016).

Observa-se que a fala do membro da comunidade - assim como as demais - tem tom de coragem, indignação e cobrança, uma tentativa de mudar a realidade por meio do discurso.

Nota-se, na fala de Re., uma relativização das relações de poder entre ela, professora da rede municipal de ensino, e A., vereador e vice-prefeito eleito. Apesar de reconhecer em A. um papel próximo ao de patrão ("como você, digamos que... é meu patrão, vamos dizer assim"), Re., além de não se intimidar, afirma-se como autorizada a dizer o que está dizendo. E faz isso relatando a sua experiência de quatro anos praticamente apenas com crianças especiais, além de ter 27 anos de experiência como docente.

Ademais, a mãe da aluna ressignifica algumas falas dos membros da mesa (o prefeito precisaria ler a constituição, de acordo com R., e os alunos seriam o futuro da nação, segundo B., por exemplo), ampliando o debate.

Outro ponto a destacar é que Re. viu na mesa-redonda a oportunidade de ser ouvida ("digamos que é a hora talvez que eu tenha para me manifestar diante de duas autoridades de nosso município"). A escola cumpriu, portanto, o seu papel de se relacionar com outros aspectos da comunidade que a rodeia. A concretização de eventos como esse faz com que as autoridades se sintam pressionadas e, quem sabe, tomem providências a respeito de tais problemas.

Como resposta a Re., um dos vereadores comprometeu-se a se dedicar à questão da acessibilidade no mandato 2017-2020.

\section{Para (não) concluir}

O relato de uma prática pedagógica mostrou a possibilidade de um ensino crítico de língua materna no Ensino Médio mediante leitura, escrita e debate. Por meio de trabalho em grupos, foi possível envolver a maioria dos alunos em atividades importantes para eles, já que consideravam o seu entorno social. Com isso, houve promoção de consciência e proposta de transformação social.

Interpretando e avaliando a experiência vivenciada, finalizo este artigo (mas não o debate) com duas reflexões: uma apontando algumas alterações necessárias no trabalho realizado, e outra sobre a (im)possibilidade de aplicação do trabalho relatado em outros contextos.

Em relação às alterações, considero que seja necessário incluir um trabalho sobre a linguagem mais claro, no sentido de explicitar ao educando a força da linguagem na legitimação de "verdades". A leitura dos contos e do romance ajudou nesse aspecto, já que os estudantes viram a possibilidade de criticar a realidade por meio da produção escrita. No entanto, faltou um trabalho cuja ênfase fosse a análise crítica de textos com ponto de vista da ideologia dominante, ou seja, textos cujos discursos justifiquem o status quo, legitimando os interesses de certos grupos sociais. Isso seria possível, por exemplo, com a leitura de reportagens e artigos de opinião veiculados local e nacionalmente. 
Alteraria, ainda, a ordem das tarefas propostas. Em vez de começar com a leitura dos contos, iniciaria com o levantamento de problemas da cidade. Assim, haveria tempo de corrigir todas as produções escritas antes da mesa-redonda. Cabe salientar que, no primeiro semestre de 2016, o último conteúdo abordado pela disciplina de Língua Portuguesa na segunda série do Ensino Médio foi a terceira fase do Romantismo, cujas produções literárias já fazem fortes críticas sociais. No início do segundo semestre, seria viável, então, retomar tal característica romântica para incitar os educandos a identificarem os problemas de sua comunidade. Assim, além de corrigir as produções a tempo, os aspectos gramaticais poderiam ser estudados a partir dos textos dos próprios alunos, o que seria mais significativo.

Além disso, disporia um período todo do dia para realização da mesa-redonda, de modo que mais estudantes pudessem realizar perguntas. Por fim, ampliaria a divulgação do evento final da disciplina, com vistas a propiciar a participação da comunidade em geral, principal interessada nos assuntos discutidos. Assim, não somente os alunos teriam voz ativa, mas outras pessoas de Presidente Epitácio.

$\mathrm{Na}$ introdução deste artigo, citei Tripp (2005) para mostrar as semelhanças entre a minha experiência pedagógica relatada neste texto e a pesquisa-ação, apontando que tal prática docente tem características parecidas com a modalidade "socialmente crítica" dessa metodologia de pesquisa. No entanto, considero que, com as alterações acima sugeridas, esta prática se aproximaria mais da modalidade "emancipatória" de pesquisaação, que, de acordo com Tripp (2005, p. 458), "tem como meta explícita mudar o status quo não só para si mesmo e para seus companheiros mais próximos, mas de mudálo numa escala mais ampla, do grupo social como um todo". Além disso, essa modalidade é mais coerente com a base teórica que sustenta a prática pedagógica relatada, a mesma referenciada neste artigo.

Saliento que a decisão em divulgar essa experiência também tem estreita relação com o posicionamento teórico assumido nas aulas e apresentado neste artigo. Além de considerar essencial que o ensino (de línguas) tenha como um de seus objetivos a minimização de injustiças sociais, entendo que a prática docente relatada possa servir de exemplo, desde que adaptada levando em conta o contexto de aplicação. No entanto, dois pontos merecem ser destacados.

O primeiro diz respeito à autonomia do professor. Trabalhos como esse exigem uma "despreocupação" (relativa) com o cumprimento total e exato do conteúdo previsto. É preciso propiciar tempo para que os alunos leiam, discutam e escrevam em sala de aula. Tarefas como a criação de um fim para o conto "A cartomante", por exemplo, demoram para ser realizadas e não devem ser vistas como perda de tempo. Em contextos em que o professor é obrigado a contemplar todo o conteúdo previsto e/ou não tem liberdade para escolher seus instrumentos de avaliação, um trabalho como o relatado fica comprometido. Nesse caso, parece-me viável ao professor, primeiramente, lutar por mais autonomia, questionando e transformando as relações de poder em seu ambiente de trabalho.

O segundo ponto, que complementa o primeiro, refere-se à situação privilegiada do contexto em que a experiência relatada ocorreu. Além de o IFSP, Câmpus Presidente Epitácio, contar com estrutura de qualidade e condições de trabalho boas quando comparadas às de outros contextos, os docentes das demais disciplinas costumam abordar temas polêmicos em suas aulas, o que contribui para a formação crítica dos educandos. 
Todavia, independentemente da realidade escolar, defendo ser possível envolver os educandos em atividades que promovam a consciência crítica e a mudança social, ainda que com pouco impacto social. Ou seja: o docente tem condições de ser "intelectual transformador", que, de acordo com Giroux (1987), é aquele que transforma, que age em sociedade em busca de justiça social.

\section{Referências}

BARBOSA, B. C.; MARTINS NETO, I. A. Heterogeneidade da escrita: "erros" ortográficos propositais em redes sociais digitais e a construção do sentido. Revista de Letras Norte@mentos, Sinop, v. 12, n. 29, p. 158-176, jul./dez. 2019.

CLARK, R., FAIRCLOUGH, N., IVANIC, R., JONES, M. Conscientização Crítica da Linguagem, tradução de Angela Kleiman e Marilda Cavalcanti. Trabalhos em Lingüística Aplicada, Campinas, v. 28, p. 37-57 jul./dez. 1996.

CORRÊA, M.L.A. Letramento e heterogeneidade da escrita no ensino de Português. In: SIGNORINI, I. (Org.). Investigando a relação oral/escrito e as teorias do letramento. Mercado de Letras: Campinas, SP, 2001, p. 135-166.

FAIRCLOUGH, N. Language and power. New York: Longman, 1989.

FRANCO JR, A. Operadores de leitura da narrativa. In: BONICCI, T.; ZOLIN, L. O. (Orgs.). Teoria Literária: abordagens históricas e tendências contemporâneas. Maringá: EDUEM, 2003, p. 22-56.

FREIRE, P. A importância do ato de ler: em três artigos que se completam. 51. ed. São Paulo: Cortez, 2011.

FREIRE, P. Pedagogia do oprimido. 59. ed. Rio de Janeiro: Paz e Terra, 2015.

GIROUX, H. A pedagogia radical e o intelectual transformador. In: GIROUX, H. $A$ escola crítica e a política cultural. São Paulo: Cortez, 1987, p. 7-53.

GREGORY, A. E.; CAHILL, M. A. Constructing critical literacy: self-reflexive ways for curriculum and pedagogy. Critical Literacy: Theories and Practicies. v. 3, p. 6-16, 2009.

HAWKINS, M.; NORTON, B. Critical language teacher education. In: BURNS, A.; RICHARDS, J. (Eds). Cambridge guide to second language education. Cambridge: Cambridge University Press, 2009, p. 30-39.

KLEIMAN, A. (Org.). Os significados do letramento: uma perspectiva sobre a prática social da escrita. Campinas, SP: Mercado de Letras, 1995.

KOMESU, F.; TENANI, L. Considerações sobre o conceito de "internetês" nos estudos da linguagem. Linguagem em (Dis)curso, Palhoça, v. 9, n. 3, p. 621-643, set./dez. 2009. 
LIBÂNEO, J. C. Adeus professor, adeus professora? Novas exigências educacionais e profissão docente.13. ed. São Paulo: Cortez, 2012.

MARTINS NETO, I. A. Adaptação, criação e juventude: diálogos entre práticas de letramento escolar e não escolar. 2020. 195 f. Tese (Doutorado em Estudos da Linguagem) - Universidade Estadual de Londrina, Londrina. 2020.

NORTON, B. Critical literacy and international development. Critical Literacy: theories and practices. CSSGJ. v. 1, 1, p. 6-15, 2007.

PAIVA, V. L. M. O. A linguagem dos emojis. Trab. Ling. Aplic., Campinas, n. 55, v. 2, p. 379-399, mai./ago. 2016.

RAMALHO, V. Ensino de língua materna e Análise de Discurso Crítica. Bakhtiniana. vol, 7, 1, p. 178-198, 2012.

SHOR, I. What is critical literacy? In: DARDER, A.; BALTODANO, M.; TORRES, R. (Eds.). The critical pedagogy reader. 2. ed. New York: Routledge, 2009, p. 282-304.

SOARES, M. B. Língua escrita, sociedade e cultura: relações, dimensões e perspectivas. In: SOARES, M. B. Alfabetização e letramento. $6^{\text {a }}$ ed. São Paulo: Contexto, 2011, p. $27-45$.

STREET, B. Letramentos sociais: abordagens críticas do letramento no desenvolvimento, na etnografia e na educação. Tradução de Marcos Bagno. São Paulo: Parábola Editorial, 2014.

TEDESCO, J. C. O novo pacto educativo: educação, competitividade e cidadania na sociedade moderna. São Paulo: Ática, 2004.

TRIPP, D. Action research: a methodological introduction. Educação e Pesquisa. v. 31, n. 3, 2005, p. 443-466.

Recebido em 10 de maio de 2020

Aceito em 12 de junho de 2020 